\title{
ANALISA PROYEK SISTEM INFORMASI VEHICLE SECURITY MENGGUNAKAN METODE ANALISIS SWOT DAN TELOS
}

\author{
Risky Kurniawan', Risan Viargi' ${ }^{2}$, Fauzi Rivano Rachmat ${ }^{3}$, Rizky Fadhilah ${ }^{4}$, \\ Ricky Firmansyah ${ }^{5}$ \\ Program Studi Sistem Informasi 1,2,3,4,5 \\ Fakultas Teknologi Informasi $1^{1,2,3,4,5}$ \\ Universitas Adhirajasa Reswara Sanjaya ${ }^{1,2,3,4,5}$ \\ riskykurniawan15@gmail.com ${ }^{1}$, risanviargi.gg@gmail.com² ${ }^{2}$,rivanofz666@gmail.com³ \\ rizkyfadhilah20@gmail.com ${ }^{4}$, ricky@ ars.ac.id ${ }^{5}$
}

\begin{abstract}
ABSTRAK
Tujuan penelitian ini ialah untuk mengetahui hasil analisa proyek sistem informasi berbasis Internet of Things (IoT) Vehicle Security dengan menggunakan teknik analisa SWOT dan uji kelayakan TELOS. Penelitian ini menggunakan penelitian kualitatif dengan pendekatan deskriptif. Teknik pengumpulan data diantaranya studi pustaka yang meliputi referensi buku dan pencarian data secara daring, serta studi lapangan yang meliputi observasi dan dokumentasi. Berdasarkan hasil penelitian, diperoleh hasil penelitian bahwa hasil Analisa SWOT dinilai positif meskipun terdapat beberapa hal yang perlu dibenahi untuk kedepannya. Sedangkan dari hasil uji kelayakan TELOS didapati hasil penilaian 8,34 atau jika dibulatkan menjadi 8 yang berarti proyek sistem informasi tersebut sangat layak untuk terus dikembangkan.
\end{abstract}

Kata kunci: Analisa Proyek; Sistem Informasi; Analisis SWOT; Uji Kelayakan TELOS; Vehicle Security

Abstract: The aim of this research was to know the analysis results of information system project based on the Internet of Things (IoT) Vehicle Security using SWOT analysis technical and TELOS feasibility test. The research was applying qualitative research with a descriptive approach. The collection information techniques were library research which include book references and internet searching, as well as field studies which include observation and documentation. Based on the results of the study, the answer of the study showed that The results of the SWOT analysis are positive although there are several things that need to be addressed in the future. Meanwhile, the results of the TELOS feasibility test show that the production results are 8.34 or if rounded to 8 , which means that the information system project is very feasible to continue to be developed.

Keywords: Project Analysis; Information System; SWOT Analysis; TELOS Feasibility Test; Vehicle Security

\section{PENDAhUluAN}

Saat ini kendaraan bermotor, baik yang beroda empat maupun dua, telah menjadi kebutuhan paling penting di Indonesia karena memudahkan kegiatan sehari-hari, membantu perpindahan manusia atau barang dari satu tempat ke tempat lainnya, dan dapat menjadi media yang menunjang pertumbuhan dan perkembangan suatu pembangunan dan ekonomi di wilayah tertentu. Saking memudahkan manusia, bahkan untuk jarak terdekat pun orang lebih memilih menggunakan kendaraan bermotor daripada berjalan kaki. Namun kadang ada juga yang membeli kendaraan bermotor untuk hal pribadi seperti mengoleksi. Dengan beberapa alasan demikian, maka kendaraan bermotor di Indonesia pun sangat membludak bahkan hingga hari ini. Jumlah kendaraan bermotor di Indonesia hampir separuh populasi penduduknya.

Kurun waktu tahun 2014 sampai 2018 penjualan mobil terbilang tinggi atau tumbuh 29,3 persen. Dari 105.575.278 unit pada 2014, menjadi 136.542.034 unit pada tahun 2018. Meski populasi kendaraan tambah besar, namun aksi kejahatan curanmor di Indonesia menurun 34,2 persen dalam waktu lima tahun, dari 42.165 kejadian pada tahun 2014, menjadi 27.731 kasus pada 2018. Lalu bagaimana dengan masa pandemi COVID-19? Sebaliknya, penjualan kendaraan bermotor turun drastis, tapi tingkat kejahatan pencurian kendaraan bermotor (curanmor) justru cenderung naik. Berdasarkan riset Lifepal Technologies Indonesia atau lifepal.co.id, meski Kepolisian Republik

JISICOM (Journal of Information System, Informatics and Computing)

http://journal.stmikjayakarta.ac.id/index.php/jisicom Telp.+62-21-3905050, e-mail:jisicom@stmikjayakarta.ac.id, jisicom2017@gmail.com 
Indonesia belum merilis data Statistik Kriminal terbaru, di masa pandemi COVID-19, sejumlah kepolisian tingkat provinsi maupun kabupaten/kota menginformasikan adanya tindak laku curanmor yang meningkat, sedangkan sebagian lainnya menurun [1]. Ketika telah terjadi curanmor, biasanya kendaraan bermotor yang telah dicuri tersebut sangat sulit untuk dilacak keberadaannya serta kemungkinan untuk didapatkan kembali masih minim.

Seiring dengan perkembangan Ilmu Pengetahuan dan Teknologi saat ini telah membawa banyak perubahan terhadap kehidupan manusia [2]. Selain itu, informasi saat ini sudah menjadi sebuah komoditi yang sangat penting. Kemampuan untuk mengakses dan menyediakan informasi secara cepat dan akurat menjadi sangat esensial bagi sebuah organisasi, baik yang berupa organisasi komersial (perusahaan), perguruan tinggi, lembaga pemerintahan, maupun individual (pribadi). Hal ini dimungkinkan dengan perkembangan pesat di bidang teknologi komputer dan telekomunikasi. Dalam hal ini informasi yang dimaksudkan adalah informasi kendaraan bermotor.

Sebagai sebuah solusi dari masalah tersebut, dibuatlah sebuah proyek sistem informasi yang dapat membantu mengamankan kendaraan bermotor dari kejahatan curanmor yaitu Vehicle Security. Proyek sistem informasi vehicle security masih tergolong proyek aplikasi yang menggunakan teknologi jenis baru dan masih sangat jarang ditemui dimasyarakat, diperlukan pengujian serta analisa untuk menentukan kelayakan proyek sistem informasi tersebut agar didapati hasil kelayakan apakah aplikasi tersebut sangat layak untuk terus dikembangkan atau proyek tersebut harus dihentikan, peneliti akan melakukan uji kelayakan TELOS pada penilaian uji kelayakan dan peneliti juga akan melakukan analisa SWOT untuk menemukan aspek-aspek penting dari kekuatan, kelemahan, peluang, dan ancaman di dalam proyek sistem informasi tersebut.

\section{METODE PENELITIAN}

\subsection{Desain Penelitian}

Penelitian ini merupakan jenis penelitian kualitatif dengan pendekatan deskriptif. Penelitian kualitatif deskriptif ditujukan untuk mendeskripsikan dan menggambarkan fenomenafenomena yang ada, baik bersifat alamiah maupun rekayasa manusia, yang lebih memperhatikan mengenai karakteristik, kualitas, keterkaitan antar kegiatan. Selain itu, penelitian deskriptif tidak memberikan perlakuan, manipulasi atau pengubahan pada variabel-variabel yang diteliti, melainkan menggambarkan suatu kondisi yang apa adanya. Satu-satunya perlakuan yang diberikan hanyalah penelitian itu sendiri, yang dilakukan melalui observasi, wawancara, dan dokumentasi [3].

Teknik analisa data yang akan digunakan dalam penelitian ini adalah teknik analisa SWOT. Analisis SWOT merupakan singkatan dari strength (kekuatan), weakness (kelemahan), opportunity (kesempatan), dan threat (ancaman). Analisis ini pertama kali diperkenalkan oleh Albert Humphrey yang memimpin proyek riset di Stanford University. Melalui analisis SWOT, kita dapat melakukan identifikasi faktor internal (strength dan weakness) dan faktor eksternal (opportunity dan threat) dari organisasi secara sistematis untuk merumuskan strategi organisasi [4].

Sedangkan uji kelayakan TELOS diperlukan untuk menentukan apakah pengembangan proyek sistem layak untuk dikembangkan atau tidak. TELOS merupakan singkatan dari Technical (Teknologi), Economic (Ekonomi), Legal (Hukum), Operational (Operasional), dan Schedule Feasibility (Kelayakan Jadwal) [5].

Peneliti akan memaparkan analisa proyek sistem informasi yang berkaitan dengan Vehicle Security dengan menggunakan teknik perencanaan strategis SWOT untuk mengevaluasi faktor-faktor yang berpengaruh dan uji kelayakan TELOS untuk mengukur nilai kelayakan sistem.

\subsection{Teknik Pengumpulan Data}

Untuk dapat menghasilkan data yang dibutuhkan dalam penelitian ini diperlukan suatu teknik yang sesuai, dan dalam penelitian ini peneliti menggunakan teknik-teknik pengumpulan data sebagai berikut:

\section{a) Studi Pustaka}

Menelusuri literatur yang ada serta menelaahnya secara tekun merupakan kerja kepustakaan yang sangat diperlukan dalam mengerjakan penelitian. Studi literatur, selain dari mencari sumber data sekunder yang akan mendukung penelitian, juga diperlukan untuk mengetahui sampai ke mana ilmu yang berhubungan dengan penelitian telah berkembang, sampai ke mana terdapat kesimpulan dan

\section{JISICOM (Journal of Information System, Informatics and Computing)}


degeneralisasi yang telah pernah dibuat, sehingga situasi yang diperlukan dapat diperoleh. Dengan mengadakan studi terhadap literatur yang telah ada, peneliti dapat belajar secara lebih sistematis tentang cara-cara menulis karya ilmiah, cara mengungkapkan buah pikiran yang akan membuat si peneliti lebih kritis dan analitis dalam mengerjakan penelitian [6]. Disini peneliti menggunakan studi pustaka dengan mencari berbagai data sebagai pendukung dari penelitian yang dilakukan oleh peneliti seperti mencari referensi buku yang dapat memberikan keterangan topik perkataan, tempat pariwisata, data statistika, pedoman, alamat, nama orang, riwayat orang-orang terkenal. Selain itu peneliti juga melakukan pencarian data seacara daring dengan mencari dan mengumpulkan informasi-informasi berupa datadata yang berkaitan dengan penelitian yang sedang diteliti oleh peneliti.

b) Studi Lapangan

Teknik ini merupakan penelitian yang dilakukan dengan cara melakukan pengamatan dalam pengumpulan data di lapangan. Pengumpulan data dari lapangan ini dilakukan untuk memperoleh data primer. Adapun teknik pengumpulan data yang dilakukan oleh penulis ialah melakukan observasi berupa pengumpulan data dengan cara mencatat, menganalisa dan selanjutnya dapat membuat kesimpulan mengenai analisa proyek sistem informasi Vehicle Security dengan menggunakan teknik analisa SWOT dan uji kelayakan TELOS. Selanjutnya peneliti melakukan dokumentasi yaitu teknik pengumpulan data berbentuk dokumentasi merupakan komponen yang cukup penting yang nantinya akan digunakan peneliti dalam memverifikasi kembali data yang diperoleh di lapangan. Selain gambar pada saat kegiatan, dokumentasi lain yang dilakukan peneliti dapat berupa catatan.

\section{PEMBAHASA DAN HASIL}

\subsection{Gambaran Umum Proyek Sistem Informasi}

Proyek Sistem informasi berupa situs web Vehicle Security menggunakan sistem berbasis web yang dibangun dengan framework codeigniter versi 3, memiliki halaman yang semi dinamis pada tampilan halaman home, dan memiliki halaman dinamis pada halaman admin panel. Sistem informasi adalah suatu sistem didalam suatu organisasi yang mempertemukan kebutuhan pengelolaan transaksi harian, mendukung operasi, bersifat manajerial, dan kegiatan strategi dari suatu organisasi dan menyediakan pihak luar tertentu dengan laporan - laporan yang dibutuhkan [7].

Sistem informasi vehicle security dibuat untuk memudahkan dalam media promosi aplikasi berbasis Internet of Things (IoT) Vehicle Security serta memudahkan penggunanya untuk mengunduh aplikasi dengan cepat dan memudahkan pula para penggunanya untuk mengelola kendaraan yang telah dihubungkan pada akun yang terdapat dalam sistem informasi tersebut. Internet of Things (IoT) adalah struktur di mana objek atau orang disediakan dengan identitas eksklusif dan kemampuan untuk pindah data melalui jaringan tanpa memerlukan dua arah antara manusia ke manusia yaitu sumber ke tujuan atau interaksi manusia ke komputer [8]. Internet of Things (IoT) merupakan perkembangan keilmuan yang sangat menjanjikan untuk mengoptimalkan kehidupan berdasarkan sensor cerdas dan peralatan pintar yang bekerjasama melalui jaringan internet [9].

Aplikasi Vehicle Security adalah aplikasi yang bertujuan untuk membantu dalam mengamankan kendaraan dari kejahatan pencurian kendaraan bermotor dengan menggunakan alarm yang dapat diakses dari jarak jauh, serta dapat mendeteksi lokasi kendaraan secara realtime. Aplikasi tersebut memiliki jenis aplikasi berbasis android yang dibuat menggunakan aplikasi MIT App Inventor dengan menggunakan sebuah platform ANTARES IoT Cloud sebagai media komunikasi data dengan konsep Machine to Machine (M2M). Aplikasi tersebut dibuat sebagai alat untuk mendukung smart city yang diharapkan dapat mengurangi kriminalitas yang terjadi pada sebuah kota. Fitur yang terdapat pada aplikasi tersebut ialah penggunaan remote aplikasi yang memudahkan untuk mengaktifkan alarm serta melacak lokasi kendaraan secara akurat dengan mengambil data berupa longitude dan latitude serta dapat dilihat secara langsung melalui aplikasi google maps.

Aplikasi sistem informasi vehicle security dapat dibuka melalui alamat http://visec.server2risoftinc.epizy.com/ dan dapat digunakan secara gratis.

\subsection{Analisa Menggunakan Metode SWOT}

Berdasarkan hasil analisa dari proyek sistem informasi Vehicle Security, kami menemukan beberapa faktor yang dapat dipertimbangkan dalam proyek sistem 
informasi yang dikembangkan. Berikut adalah hasil analisa proyek sistem informasi dengan menggunakan metode alnalisis SWOT.

a) Faktor Kekuatan (Strength)

Aplikasi sistem informasi Vehicle Security memiliki fitur yang menarik, yakni dapat mengelola kendaraan yang tersimpan pada aplikasi serta memiliki fitur yang menarik pada produk yang dihasilkan diantaranya dapat melakukan remote aplikasi untuk mengaktifkan alarm kendaraan serta melacak lokasi kendaraan secara akurat menggunakan longitude dan latitude kendaraan.

b) Faktor Kelemahan (Weakness)

Aplikasi masih sangat bergantung terhadap akses internet serta produk yang dihasilkan masih tergolong dalam kategori produk baru sehingga masih kurangnya kepercayaan masyarakat akan produk yang diusung dalam proyek sistem informasi tersebut.

c) Faktor Peluang (Opportunities)

Masih sedikitnya aplikasi yang serupa sehingga proyek berpotensi menjadi pionir dalam kategori alat pengaman kendaraan dengan menggunakan teknologi Internet of Things (IoT).

d) Faktor Ancaman (Threats)

Regulasi belum terlalu matang serta dibutuhkan kecekatan dalam melakukan promosi sehingga proyek yang direncanakan tidak menjadi sebuah produk yang gagal di pasaran.

\subsection{Analisa Uji Kelayakan TELOS}

a) Kelayakan Teknis (Technical)

Teknologi yang digunakan dalam proyek sistem informasi vehicle security menjadi acuan utama sebagai faktor kelayakan teknis yang dapat menentukan apakah produk yang dihasilkan dari proyek tersebut dapat bersaing dipasaran ataupun tidak. Jika dalam sistem yang hendak dikembangkan menggunakan teknologi yang stabil dan sudah diketahui atau dipakai secara umum maka nilai kelayakan teknik antara 9.5 sampai 10 . Namun jika teknologi tersebut dianggap baru atau belum dipakai secara umum sehingga butuh keluaran terbaru dari pemasok maka penilaian antara 6 sampai 8 [10]. Berikut kami sampaikan hasil analisa sesuai faktor teknis yang terdapat dalam proyek sistem informasi tersebut.

Kebutuhan sistem aplikasi dari proyek sistem informasi vehicle security dapat berjalan dengan spesifikasi komputer dan mobile (android) yang tidak terlalu berat, berikut adalah spesifikasi kebutuhan sistem yang ada.

\begin{tabular}{|l|l|}
\multicolumn{2}{l}{ Tabel 1. Kebutuhan Sistem } \\
\hline $\begin{array}{l}\text { Sistem } \\
\text { Operasi }\end{array}$ & Kebutuhan Minimal \\
\hline Windows, & Processor Minimal berkecepatan 1.5 \\
Mac, & GHZ atau lebih, Penyimpanan \\
Linux & $100 \mathrm{MB}$, Ram 1Gb, VRam 128MB \\
\hline Android & $\begin{array}{l}\text { Processor Minimal berkecepatan 1 } \\
\text { GHZ atau lebih, Penyimpanan }\end{array}$ \\
& $100 \mathrm{MB}$, Ram 1Gb \\
\hline
\end{tabular}

Infrastruktur teknologi yang ada menjadi tolak ukur selanjutnya yang perlu dipertimbangkan dalam uji kelayakan teknis, akses internet yang mumpuni serta stabil menjadi acuan utama aplikasi dapat berjalan dengan baik tanpa adanya sebuah hambatan. Infrastruktur teknologi terutama akses internet di Indonesia masih belum mumpuni sehingga produk yang dihasilkan tidak dapat berjalan dengan baik ketika pengguna berada pada area yang tidak terjangkau internet dengan baik.

Selanjutnya adanya kebutuhan perangkat lunak yang digunakan agar aplikasi dapat berjalan dengan optimal, kebutuhan perangkat yang diperlukan ialah sebagai berikut:

Tabel 2. Kebutuhan Perangkat Lunak

\begin{tabular}{|l|l|}
\hline Perangkat Lunak & Jenis Perangkat \\
\hline Browser & $\begin{array}{l}\text { Google Chrome, Safari, } \\
\text { Mozila, Ms Edge, Dll }\end{array}$ \\
\hline
\end{tabular}

Dalam proses alur aplikasi yang dibuat, agar aplikasi dapat berjalan dengan baik maka diperlukan beberapa perangkat keras yang harus digunakan diantaranya sebagai berikut:

Tabel 3. Kebutuhan Perangkat Keras

\begin{tabular}{|l|l|}
\hline Nama Perangkat & Jumlah \\
\hline Microcontroller & 1 Buah \\
\hline Modul Relay & 3 Chanel \\
\hline Modul SIM800L & 1 Buah \\
\hline Modul GPS & 1 Buah \\
\hline Kabel Jumper & Sesuai Kebutuhan \\
\hline
\end{tabular}

b) Kelayakan Ekonomi (Economic)

Kelayakan ekonomi berfokus pada apakah sistem harus dibangun dengan didalamnya terdapat analisis biaya dan manfaat [10]. Faktor ekonomi menjadi salah satu faktor berikutnya yang kami

JISICOM (Journal of Information System, Informatics and Computing)

http://journal.stmikjayakarta.ac.id/index.php/jisicom Telp.+62-21-3905050, e-mail:jisicom@stmikjayakarta.ac.id, jisicom2017@gmail.com 
gunakan sebagai analisa uji kelayakan proyek sistem informasi, Batasan dari analisa faktor ekonomi meliputi perhitungan modal yang dikeluarkan serta keuntungan dari proyek yang dijalankan. Berikut ialah tabel perhitungan modal proyek dan modal produksi serta sumber pendanaan:

Tabel 4. Modal Proyek dan Sumber Dana

\begin{tabular}{|l|l|l|}
\hline Nama Modal & Jumlah & $\begin{array}{l}\text { Sumber } \\
\text { dana }\end{array}$ \\
\hline $\begin{array}{l}\text { Laptop } \\
\text { Komputer }\end{array}$ & $\begin{array}{l}\text { Rp. } \\
5.990 .000\end{array}$ & Pribadi \\
\hline $\begin{array}{l}\text { Pendaftaran } \\
\text { HAKI }\end{array}$ & $\begin{array}{l}\text { Rp. } \\
600.000\end{array}$ & Donatur \\
\hline Paket Hosting & Rp. 0 & Gratis \\
\hline Paket Domain & Rp. 0 & Gratis \\
\hline Biaya Internet & $\begin{array}{l}\text { Rp. } \\
206.000\end{array}$ & Donatur \\
\hline Total & $\begin{array}{l}\text { Rp. } \\
6.796 .000\end{array}$ & \\
\hline
\end{tabular}

Tabel 5. Modal Produksi dan Sumber Dana

\begin{tabular}{|l|l|l|}
\hline Nama Modal & Jumlah & $\begin{array}{l}\text { Sumber } \\
\text { dana }\end{array}$ \\
\hline Microcontroller & Rp. 46.000 & Pembelli \\
\hline $\begin{array}{l}\text { Modul Relay 3 } \\
\text { chanel }\end{array}$ & Rp. 24.000 & Pembelli \\
\hline Modul SIM800L & Rp. 9.000 & Pembelli \\
\hline Modul GPS & Rp. 55.000 & Pembelli \\
\hline $\begin{array}{l}\text { Kabel Jumper / } \\
\text { 40pcs }\end{array}$ & Rp. 13.000 & Pembelli \\
\hline Total & Rp. 147.000 & \\
\hline
\end{tabular}

Keuntungan dari proyek didapat dari 2 hal utama yakni dari jenis akses pengguna serta penjualan perangkat pengaman kendaraan. Biaya modal keperluan proyek didapatkan sejumlah $\mathrm{Rp}$. 6.796.000 dan didapati modal yang diberikan oleh donator sejumlah Rp. 806.000 sehingga keuntungan yang harus diperoleh sejumlah Rp. 5.990 .000 yang bersumber dari jenis akses pengguna aplikasi yang kami berikan bebannya sebanyak Rp. 300.000 per akun pengguna. Sehingga untuk menutupi modal diperlukan minimalnya 20 pengguna yang melakukan upgrade akun. Sedangkan untuk modal produksi berjumlah Rp. 147.000 yang hasil rakitannya dijual kembali sejumlah Rp. 350.000 sehingga dalam 1 unit penjualan produk didapati laba sejumlah Rp. 203.000 . c) Kelayakan Hukum (Legal / Law)

Faktor legalitas atau hukum perlu dipertimbangkan, jika sebuah proyek melanggar hukum tentu sangat beresiko jika dikembangkan. Menilai Kelayakan Hukum, biasanya legalitas dari suatu proyek bukan sebuah permasalahan. Sehingga nilai kelayakan ini sangat mungkin bernilai 10. Namun jika data yang dimiliki bernilai sensitif yang berakibat managemen berurusan dengan hukum dikarenakan kesalahan terhadap data maka penilaian kelayakan 9.5 [10]. Dalam penilaian kelayakan pada faktor hukum ini kami membaginya kedalam beberapa bagian seperti kelayakan hukum, lisensi dan template yang digunakan dalam proyek sistem informasi tersebut.

Dalam kelayakan hukum pada aplikasi sistem informasi yang dibuat dalam proyek tersebut bukan termasuk dari hal yang dilarang oleh hukum di Indonesia, aplikasi bukan termasuk dalam kategori penipuan ataupun dalam kategori pornografi. Dalam bentuk kepastian hukum aplikasi sistem informasi tersebut telah didaftarkan kepada Kementerian Hukum dan Ham dalam kategori Hak Cipta dengan nomor aplikasi EC00202026781.

Lisensi aplikasi menjadi faktor dominan yang menjadi tolak ukur tentang legalitas hukum dari proyek yang dibuat, berikut adalah tabel data aplikasi serta template yang digunakan dalam proyek sistem informasi tesebut beserta lisensinya.

Tabel 6. Aplikasi dan Template Proyek

\begin{tabular}{|l|l|}
\hline $\begin{array}{l}\text { Aplikasi dan } \\
\text { template }\end{array}$ & Lisensi \\
\hline XAMPP & $\begin{array}{l}\text { GNU General Public } \\
\text { Licence }\end{array}$ \\
\hline VScode & MIT license \\
\hline AdminLTE-3.0.4 & MIT license \\
\hline Appson & $\begin{array}{l}\text { CC BY 3.0 (footer credits } \\
\text { must remain in place) }\end{array}$ \\
\hline Arduino & $\begin{array}{l}\text { Creative Commons } \\
\text { Attribution-ShareAlike } \\
\text { 3.0 License }\end{array}$ \\
\hline MIT App Inventor & $\begin{array}{l}\text { Creative Commons } \\
\text { Attribution-ShareAlike } \\
\text { 4.0 International License. }\end{array}$ \\
\hline
\end{tabular}

d) Kelayakan Operasional (Operational)

Faktor operasional diperlukan untuk mengetahui kelayakan dari penggunaan sistem informasi yang dibuat dalam sebuah proyek, dalam

JISICOM (Journal of Information System, Informatics and Computing)

http://journal.stmikjayakarta.ac.id/index.php/jisicom Telp.+62-21-3905050, e-mail:jisicom@stmikjayakarta.ac.id, jisicom2017@gmail.com 
analisa kelayakan operasional proyek tersebut, kami menggunakan kerangka PIECES. Kerangka PIECES meliputi performance, information, economy, control, efficiency, services [10]. Kerangka PIECES digunakan untuk melihat perbandingan sebelum adanya sistem informasi tersebut dengan ketika adanya sistem informasi Vehicle Security. Menilai Kelayakan Operasional, penilaian kelayakan operasional menilai adanya pengguna yang terlatih dengan baik dan berdedikasi untuk menjalankan sistem. Namun jika pengguna adalah pengguna yang tidak terlatih dengan baik sehubungan dengan kinerja mereka maka penilaian kelayakan 7 [10]. Berikut hasil penilaian kelayakan operasional:

Tabel 7. Performance (kinerja sistem)

\begin{tabular}{|l|l|}
\hline Sebelum & Sesudah \\
\hline $\begin{array}{l}\text { Waktu yang diperlukan } \\
\text { untuk mengetahui lokasi } \\
\text { kendaraan terakhir } \\
\text { relatif lebih lambat }\end{array}$ & $\begin{array}{l}\text { Waktu ung } \\
\text { diperlukan antuk } \\
\text { mengetahui lokasi } \\
\text { kendaraan terakhir } \\
\text { relatif lebih cepat }\end{array}$ \\
\hline $\begin{array}{l}\text { Pengendalian alarm } \\
\text { kendaraan berbatas jarak } \\
\text { atau bahkan sulit } \\
\text { dilakukan }\end{array}$ & $\begin{array}{l}\text { Pengendalian alarm } \\
\text { kendaraan dapat } \\
\text { dilakukan dengan } \\
\text { mudah dan tidak } \\
\text { berbatas jarak }\end{array}$ \\
\hline
\end{tabular}

Tabel 8. Information (informasi)

\begin{tabular}{|l|l|}
\hline Sebelum & Sesudah \\
\hline $\begin{array}{l}\text { Informasi tidak akurat } \\
\text { atau bahkan sulit } \\
\text { didapat. }\end{array}$ & $\begin{array}{l}\text { Informasi jauh lebih } \\
\text { akurat. }\end{array}$ \\
\hline
\end{tabular}

Tabel 9. Economy (ekonomi)
\begin{tabular}{|l|l|}
\hline Sebelum Sesudah \\
\hline Sulitnya pelacakan dan & $\begin{array}{l}\text { Mudahnya pelacakan } \\
\text { kurangnya pengamanan } \\
\text { dan pengamanan }\end{array}$ \\
membuat kerugian yang & membuat kerugian \\
timbul jauh lebih & yang ditanggung \\
banyak. & $\begin{array}{l}\text { pengguna dapat lebih } \\
\text { diminimalisir }\end{array}$ \\
\hline
\end{tabular}

Tabel 10. Control (pengendalian)

\begin{tabular}{|l|l|}
\hline Sebelum & Sesudah \\
\hline Sulitnya pelacakan dan & Mudahnya pelacakan \\
kurangnya pengamanan & dan pengamanan \\
membuat kerugian yang & membuat kerugian \\
timbul jauh lebih & yang ditanggung \\
banyak. & pengguna dapat lebih \\
& diminimalisir \\
\hline
\end{tabular}

Tabel 11. Efficiency (efisiensi)

\begin{tabular}{|lr|lr|}
\hline Sebelum & Sesudah \\
\hline Secara default & Terintegrasi dengan \\
kendaraan tidak & system dan memiliki \\
memiliki keamanan & keamanan yang \\
kecuali dengan metode & efisien. \\
konvensional. & & \\
\hline
\end{tabular}

Tabel 12. Services (pelayanan)

\begin{tabular}{|l|lr|}
\hline Sebelum & \multicolumn{3}{|l|}{ Sesudah } & \\
\hline Sangat & \multicolumn{3}{|l|}{ Terjadinya service } & (pelayanan) \\
kecil atau & Ketika terjadinya & kehilangan \\
tidak & kendaraan berupa pelacakan \\
service & \multicolumn{3}{|l}{ kendaraan dan pengendalian jarak } \\
(pelayanan) & jauh serta dapat membantu pihak \\
ketika & terkait untuk memudahkan \\
kendaraan & pelayanan dalam r pencarian \\
hilang. & kendaraan & \\
\hline
\end{tabular}

e) Kelayakan Jadwal (Schedule)

Faktor kelayakan jadwal adalah faktor selanjutnya yang kami berikan penilaian dalam metode uji kelayakan proyek sistem informasi tersebut. Pengukuran kesalahan estimasi waktu adalah kunci keberhasilan. Jika sistem terlihat sederhana, standar dan berbasis local dimana total waktu pengembangan diukur dalam jam atau hari maka kesalahan perkiraan (estimation error) yang dibutuhkan dalam perancangan dan implementasi menjadi kecil. Tetapi jika sistem adalah enterprise wide membutuhkan total waktu dalam tahun maka probabilitas kesalahan estimasi semakin tinggi [10]. Dalam proses penilaian tersebut kami melakukan penilaian dari tahapan proyek yang terdapat pada proyek sistem informasi serta manajemen waktu yang ada. Berikut adalah jadwal dari proyek sistem informasi Vehicle Security: 


\begin{tabular}{|c|l|c|c|c|}
\hline \multicolumn{1}{|c|}{ Nama Kegiatan } & Durasi & Mulai & Berakhir \\
\hline * & Pembuatan Proyek Sistem Informasi Vehicle Security & 31 hari & 14.07 .20 & 13.08 .20 \\
\hline 1 & Perencanaan dan analisa masalah & 5 hari & 14.07 .20 & 18.07 .20 \\
\hline 2 & Pembuatan Aplikasi Vehicle Security & 5 hari & 18.07 .20 & 22.07 .20 \\
\hline 3 & Testing Aplikasi Vehicle Security & 3 hari & 22.07 .20 & 24.07 .20 \\
\hline 4 & Peluncuran Aplikasi Vehicle Security & 1 hari & 24.07 .20 & 24.07 .20 \\
\hline 5 & Pembuatan Aplikasi Sistem Informasi & 6 hari & 24.07 .20 & 29.07 .20 \\
\hline 6 & Peluncuran Aplikasi Kepada Publik & 1 hari & 29.07 .20 & 29.07 .20 \\
\hline 7 & Pembuatan Laporan Analisa Sistem Informasi & 6 hari & 30.07 .20 & 04.08 .20 \\
\hline 8 & Pembuatan Dokumen Aplikasi & 5 hari & 04.08 .20 & 08.08 .20 \\
\hline 9 & Pengumpulan Persyaratan HAKI & 5 hari & 04.08 .20 & 08.08 .20 \\
\hline 10 & Pengajuan HAKI & 5 hari & 09.08 .20 & 13.08 .20 \\
\hline
\end{tabular}

Gambar 1. Jadwal proyek sistem informasi vehicle security

\subsection{Hasil Analisa Proyek Sistem Informasi}

Hasil analisa proyek sistem informasi Vehicle Security didapati hasil analisa SWOT yang positif meskipun terdapat beberapa hal yang perlu dibenahi untuk kedepannya. Selain dari hasil penilaian SWOT kami melakukan penilaian dengan uji kelayakan TELOS (1) dimana huruf T berarti penilaian Technical, E berarti Economic, L adalah Legal/Law, O adalah Operational dan $\mathrm{S}$ adalah Schedule dengan hasil penilaian sebagai berikut:

$$
\text { Nilai }=\frac{T+E+L+O+S}{5}
$$

\section{KESIMPULAN}

Berdasarkan dari pembahasan sebelumnya, maka peneliti mengambil kesimpulan mengenai Proyek sistem informasi Vehicle Security menggunakan sistem berbasis web yang dibangun dengan framework codeigniter versi 3 yang dibuat untuk memudahkan dalam media promosi aplikasi berbasis Internet of Things (IoT). Selain itu, terdapat aplikasi berbasis mobile yang bertujuan untuk membantu dalam mengamankan kendaraan dari kejahatan pencurian kendaraan bermotor dengan menggunakan alarm yang dapat diakses dari jarak jauh, serta dapat mendeteksi lokasi kendaraan secara realtime. Pada metode analisis SWOT diketahui kekuatan pada aplikasi ini memiliki fitur yang menarik dan berpotensi menjadi pionir dalam aplikasi serupa. Meski demikian masih sangat bergantung pada akses internet dan regulasi yang belum terlalu matang. Pada uji kelayakan TELOS diketahui bahwa aplikasi dapat bersaing di pasaran karena

$$
\begin{aligned}
& \text { Nilai }=\frac{7+7,9+9,4+8,7+8,7}{5} \\
& \text { Nilai }=\frac{41,7}{5} \\
& \text { Nilai }=8,34 \sim 8
\end{aligned}
$$

Dari hasil penilaian menggunakan uji kelayakan TELOS (4) kami mendapati hasil penilaian 8,34 atau jika dibulatkan menjadi 8 yang berarti proyek sistem informasi tersebut sangat layak untuk terus dikembangkan.

spesifikasi komputer dan mobile yang dibutuhkan tidak terlalu berat. Selain itu keuntungan dari aplikasi bisa didapatkan dari jenis akses pengguna serta penjualan perangkat pengaman kendaraan. Dari sisi kelayakan hukum, aplikasi ini telah didaftarkan kepada Kementerian Hukum dan Ham dan tidak termasuk dalam hal yang dilarang oleh hukum di Indonesia. Kemudian aplikasi ini dapat dinilai layak operasional dengan melihat hasil perbandingan sebelum adanya sistem informasi tersebut dengan ketika adanya sistem informasi Vehicle Security dengan menggunakan kerangka PIECES. Dari sisi kelayakan jadwal kami telah mampu mengimplementasikan proyek ini dalam kerangka waktu yang dapat diterima. Pada hasil penilaian menggunakan uji kelayakan TELOS kami mendapati hasil penilaian $\mathbf{8 , 3 4}$ atau jika dibulatkan menjadi 8 yang berarti proyek sistem informasi tersebut sangat layak untuk terus dikembangkan. Adapun saran agar sistem ini dapat digunakan sesuai dengan yang diharapkan, maka ada beberapa saran yang dapat dijadikan bahan pertimbangan

\section{JISICOM (Journal of Information System, Informatics and Computing)}

http://journal.stmikjayakarta.ac.id/index.php/jisicom Telp.+62-21-3905050, e-mail:jisicom@stmikjayakarta.ac.id, jisicom2017@gmail.com 


\section{Journal of Information System, Informatics and Computing}

yaitu dari segi regulasi yang belum terlalu matang serta dibutuhkan kecekatan dalam media promosi dikarenakan produk yang dihasilkan masih tergolong dalam kategori produk baru sehingga masih kurangnya kepercayaan masyarakat akan produk yang diusung. Segi tersebut harus dibenahi karena meskipun masih tergolong produk baru, aplikasi Vehicle Security ini memiliki peluang besar dinegara Indonesia yang memiliki statistik

\section{REFERENASI}

[1] N. Ray, "Penjualan Otomotif Turun, Kejahatan Curanmor Justru Naik di Masa Pandemi," otosia.com, 2020.

https://www.otosia.com/berita/penjualanotomotif-turun-kejahatan-curanmor-justru-naikdi-masa-pandemi.html (accessed Oct. 22, 2020).

[2] E. Iswandy, "Analisa Dan Perancangan Sistem Informasi Penagihan Purchasing Order Customer Studi Kasus Pada Cv. Vertical Cipta Relasi Padang Dengan Metode Centralized Data Processing," J. TEKNOIF, 2016.

[3] Sukmadinata and N. Syaodih, Metode penelitian pendidikan. Bandung: Remaja Rosdakarya, 2016.

[4] Elviawan, "Analisis SWOT," tokoharits, 2018. https://tokoharits.com/blog/16_analisis-swot/ (accessed Oct. 08, 2020). kriminal pencurian kendaraan yang masih sangat tinggi. Selain itu saran yang dapat diberikan bagi para peneliti selanjutnya ialah penilaian sistem informasi berupa penilaian penerimaan teknologi terhadap pengguna yang dilakukan penilaian menggunakan model penilaian lain seperti model TAM,UTAUT, DeLone and McLean dsb.

[5] J. A. Hall, Accounting Information Systems. 2010.

[6] M. Nazir, Metode Penelitian. Bogor: Ghalia Indonesia, 2014.

[7] J. Hutahaean, Konsep Sistem Informasi, 1st ed. Yogyakarta: Deepublish, 2015.

[8] A. W. Burange and H. D. Misalkar, "Review of Internet of Things in development of smart cities with data management \& privacy," 2015, doi: 10.1109/ICACEA.2015.7164693.

[9] S. L. Keoh, S. S. Kumar, and H. Tschofenig, "Securing the internet of things: A standardization perspective," IEEE Internet Things J., 2014, doi: 10.1109/JIOT.2014.2323395.

[10] S. Syaifullah and J. Widianto, "STUDI KELAYAKAN SISTEM INFORMASI AKADEMIK BERBASIS WEB PADA POLTEKES KEMENKES RIAU DENGAN MENGGUNAKAN METODE KELAYAKAN TELOS," J. Sains dan Teknol. Ind., 2014.

JISICOM (Journal of Information System, Informatics and Computing) http://journal.stmikjayakarta.ac.id/index.php/jisicom Telp.+62-21-3905050, e-mail:jisicom@stmikjayakarta.ac.id, jisicom2017@gmail.com 